\title{
The control of tan spot of wheat (caused by Pyrenophora tritici-repentis: a possible emerging disease in New Zealand
}

\author{
I.C. Harvey ${ }^{1}$, R.A. Craigie ${ }^{2}$ and B.L. McCloy ${ }^{3}$ \\ ${ }^{1}$ PLANTwise Services Ltd, PO Box 69181, Lincoln 7640, New Zealand \\ ${ }^{2}$ Foundation for Arable Research, PO Box 23133, Templeton, Christchurch, New Zealand \\ ${ }^{3}$ New Zealand Arable, PO Box 16101, Christchurch 8001, New Zealand \\ Corresponding author: harveyi@plantwise.co.nz
}

\begin{abstract}
Pyrenophora tritici-repentis, the cause of tan spot of wheat was first recorded in New Zealand in 1979, but only on wheat seed. However, this pathogen has recently been recorded as causing possible yield losses in isolated crops. A small plot trial set up in a central Canterbury crop of cv. Saracen tested several fungicides alone or in mixtures. Control was not entirely effective since tan spot infection was well established when the first applications were made at GS33 (third node detectible). Nevertheless, two triazoles (propiconazole and prothioconazole) and three SDHI fungicides (isopyrazam, bixafen plus prothioconazole and fluxapyroxad plus epoxiconazole) all gave similar levels of control either when applied alone or in mixtures. Two triazoles (epoxiconazole and difenoconazole) were less effective alone, while addition of strobilurin (pyraclostrobin) to mixtures gave little extra control. Several treatments showed significant increases in green leaf retention and final grain yield. The life cycle of the pathogen dictates that management of the over-wintering inoculum in stubble is a probable essential step in control of the disease.
\end{abstract}

Keywords Pyrenophora tritici-repentis, tan spot, wheat, fungicides.

\section{INTRODUCTION}

Tan spot of wheat is caused by the necrotrophic fungal pathogen - Pyrenophora tritici-repentis (Died.) Drechsler. The anamorph or asexual phase is known as Drechslera tritici-repentis (Died.) Shoemaker. This is reported to be a serious and often devastating disease in many parts of the world including Australia, Asia, Europe and the Americas (CABI 2013, De Wolf et al. 1998). There are eight known races of the fungus worldwide (Antoni et al. 2010) based on the presence or absence of three host-specific toxin effectors viz. ToxA, ToxB and ToxC. In Australia, only the genes coding for ToxA were found to be present in the fungus (Antoni et al. 2010), where the disease is known as yellow spot or yellow leaf spot. Elsewhere in the world it is known as tan spot.

The pathogen was first detected in New Zealand in 1976, when it was recorded on a sample of wheat seed from Wanganui tested at the government Seed Testing Laboratory in Palmerston North (Hampton \& Matthews 1978; herbarium ref. PDD 50719). Officially, it was only recorded as a pathogen of wheat in the field in 2013, when samples were deposited by the senior author in the Landcare Research herbarium 
(ref. PDD 103136). This was from a crop of cv. Wakanui grown in Willowbridge near Waimate in South Canterbury.

Prior to these records, anecdotal reports of the presence of the disease were made by the senior author from diseased wheat samples sent to the MAF Plant Health Diagnostic Laboratory in Lincoln in 1980 and from a Bayer fungicide trial in Rakaia, Mid Canterbury, in 2011. Neither of these finds was officially recorded. The race or races of the populations causing tan spot in New Zealand is not known but is currently being investigated (S.K. Weith, Lincoln University, personal communication).

Following the reports of tan spot in wheat crops in Canterbury in the 2012-13 season, the Foundation for Arable Research initiated a series of fungicide trials in areas throughout Canterbury in 2013-14 in known or suspected susceptible wheat cultivars in areas where the disease occurred the previous season. The disease was reported early in the season in a crop of $\mathrm{cv}$. Saracen in Greendale in central Canterbury. This trial site was the only one with the disease; the other sites had symptoms of speckled leaf blotch caused by Zymoseptoria tritici, which can closely resemble those of tan spot in the early stages of development. The aim of this sole field trial was to determine the efficacy of a range of fungicides on this possibly emerging disease and its effect on final grain yield.

\section{MATERIALS AND METHODS}

A randomised complete block fungicide trial (13 treatments by 4 replicates) was sprayedout with glyphosate herbicide at early tillering (approximately GS24) in a farmer's crop of irrigated (150 $\mathrm{mm}$ in 5 passes) wheat cv. Saracen (drilled 14 May 2013) at Greendale, central Canterbury as $11 \times 3 \mathrm{~m}$ plots with $400 \mathrm{~mm}$ interplot separation and $1000 \mathrm{~mm}$ separation from the main crop.

The first of the three fungicidal spray treatments (Table 1) was applied on 30 October 2013 at GS33 (Table 2) and the last on 10 December 2013 at GS65.

Assessments for tan spot symptoms were made at GS33 (time of first fungicide application), GS55 (half ear emerged on 22 November), GS69 (flowering completed on 9 December) and GS85 (soft dough on 28 December). At GS33, 40 plants were collected in a $\mathrm{W}$ pattern across the trial area and assessed for disease. At all other assessments, 10 representative plants were collected per plot and assessed for percentage leaf area affected by disease or on the last assessment, the percentage green leaf area retained. The location of the leaves assessed up or down the plants was determined by how advanced the disease was at the time of assessment or the amount of green leaf area that was retained.

Yield was assessed by harvesting plots with a "Sampo" (Sampo Rosenlew Ltd, Pori, Finland) plot combine harvester on 24 January 2014,

Table 1 Fungicide product codes and application rates used in the trial. The water rate was 250 litres/ha.

\begin{tabular}{llllc}
\hline & & & \multicolumn{2}{l}{ Application rate $(\mathrm{ml} / \mathrm{ha})$} \\
\cline { 4 - 5 } Code & Trade name & Active ingredient(s) (ai) & Product $\left(^{1}\right)$ & ai \\
\hline epox & Opus $^{\circledR}$ & epoxiconazole & $500(1000)$ & 62.5 \\
proth & Proline $^{\circledR}$ & prothioconazole & $400(4-800)$ & 100 \\
prop1 & Tilt $^{\circledR} \mathrm{EC}$ & propiconazole & $250(500)$ & 62.5 \\
prop2 & Tilt $^{\circledR} \mathrm{EC}$ & propiconazole & $500(500)$ & 125 \\
pyrac & Comet $^{\circledR}$ & pyraclostrobin & $400(800)$ & 100 \\
isopy & Seguris flexi $^{\circledR}$ & isopyrazam & $600(600)$ & 75 \\
pro+bix & Aviator Xpro $^{\circledR}$ & prothioconazole+bixafen & $700(1000)$ & $52.5+105.5$ \\
epx+flux & Adexar $^{\circledR}$ & epoxiconazole+fluxapyroxad & $1000(1250)$ & $62.5+62.5$ \\
difen & Score $^{\circledR} 250 \mathrm{EC}$ & difenoconazole & $250^{2}$ & 62.5 \\
\hline
\end{tabular}

${ }^{1}$ Recommended label rates in brackets.

${ }^{2}$ No recommendation for use in cereals. 
Table 2 Fungicide treatments and timing.

\begin{tabular}{lccc}
\hline Treatment no. & \multicolumn{3}{c}{ Date and growth stage } \\
\cline { 2 - 4 } & $\begin{array}{r}\text { 30 October GS33 } \\
\left(3^{\text {rd }} \text { node detectable) }\right.\end{array}$ & $\begin{array}{c}\text { 21 November GS 39 } \\
\text { (Flag blade visible) }\end{array}$ & $\begin{array}{c}\text { 10 December GS69 } \\
\text { (End of flowering) }\end{array}$ \\
\hline 1 & nil & nil & nil \\
2 & epox & epox & Epox \\
3 & proth & proth & Proth \\
4 & prop1 & prop1 & prop1 \\
5 & prop2 & prop2 & prop2 \\
6 & prop1 & prop1+pyrac & prop1+pyrac \\
7 & proth & proth+pyrac & proth+pyrac \\
8 & epox & epox+pyrac & epox+pyrac \\
9 & prop1 & proth+isopy & Proth+isopy \\
10 & proth & pro+bix & Pro+bix \\
11 & prop1 & epx+flux & Epx+flux \\
12 & difen & difen & difen \\
\hline
\end{tabular}

where the plot yields were weighed on board with load cells. Statistical analysis was by ANOVA using Genstat ${ }^{\circledR} 17$ (VSN International) on plot assessments and yield data. Statistical significance was assessed as $\mathrm{P}<0.05$.

\section{RESULTS}

Tan spot was the only disease detected in the crop.

When the first assessment was made at GS33, true leaves 3 and 4 up the plant were showing typical symptoms of tan spot (Figure 1). Conidiophores and conidia of the anamorph of the pathogen were readily detected after collected leaves were subjected to warm humid laboratory conditions for 24 to $48 \mathrm{~h}$ (Figure 2). The disease incidence in the field was $100 \%$ of plants infected. Leaf 3 up the plant had $40 \%$ leaf area affected (\%LAA) by tan spot while leaf 4 had 15\% LAA.
At the second assessment at GS55 on the 22 November, the effect of the first application of fungicides was evident in the plots with prothioconazole and propiconazole (at both rates of application) giving significant reductions in \%LAA by tan spot on leaf three down from the flag (Figure 3). Difenconazole had no effect on the disease and epoxiconazole gave a nonsignificant reduction in the severity of infection.

The third assessment at the end of flowering on 9 December was on the flag leaf and the next leaf down (Flag -1) and showed that the disease was not fully controlled by any of the treatments applied at that point in the trial. The best treatments only gave an approximate $50 \%$ reduction in mean disease severity over these two top leaves (Figure $4)$. Note that only the first two spray timings had been applied at this assessment.
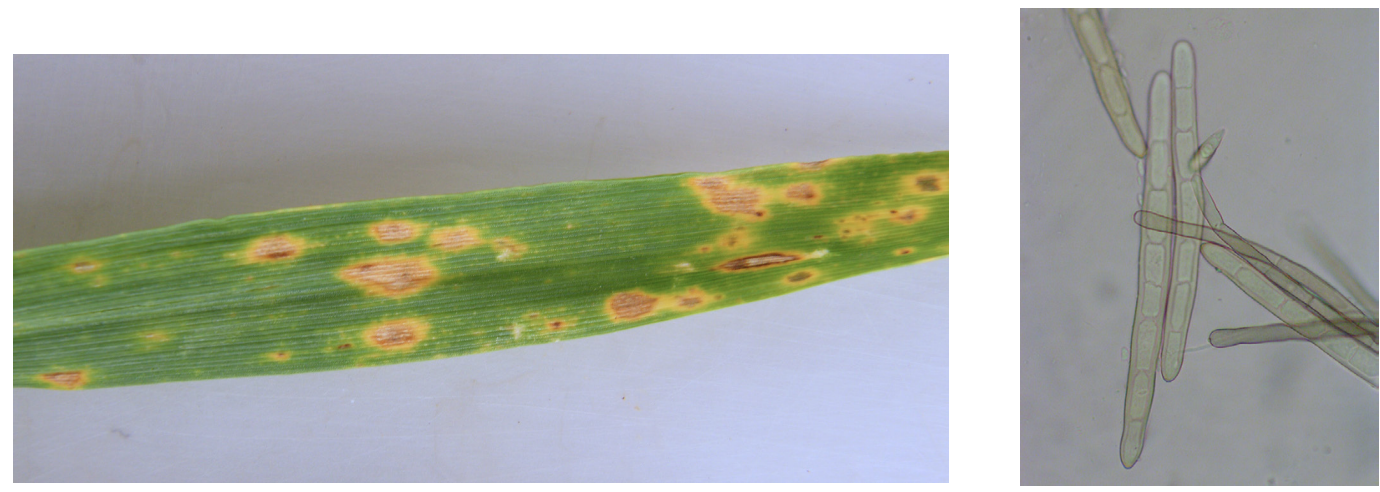

Figure 1 Symptoms of tan spot on a wheat leaf cv. Saracen.
Figure 2 Conidia and conidiophores of Pyrenophora tritici-repentis, the cause of $\tan$ spot of wheat. 


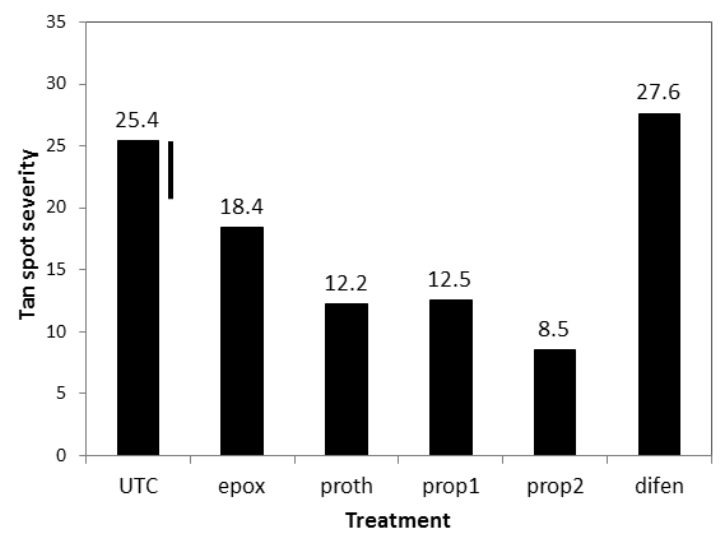

Figure 3 The severity (percent leaf area affected) of tan spot on leaf 3 down from the flag of wheat cv. Saracen assessed at GS55 on 22 November 2013 after treatment with three triazole fungicides. UTC $=$ untreated control. Bar indicates LSD $(\mathrm{P}=0.05)=7.4$.

The addition of the strobilurin pyraclostrobin to the triazoles prothioconazole, epoxiconazole or propiconazole in the second application of fungicide had no significant effect on the level of control of tan spot. The SDHI (succinate dehydrogenase inhibitor)-containing fungicide products isopyrazam, prothioconazole plus bixafen and epoxiconazole plus fluxapyroxad gave no better control that the triazoles when applied at the second application. Propiconazole and prothioconazole were the best performing triazoles compared to epoxiconazole and difenconazole.
The final disease assessment at GS85 (soft dough stage) on 28 December gave an indication as to the efficacy of the triple treatments applied up until the end of flowering. However, at this stage in the trial, the plants were rapidly losing green leaf tissue and the combination of early natural senescence and continued aggressive pathogen activity meant that only the percentage green leaf retention was able to be assessed. Thus the percentage green leaf area (\%GLA) was an inverse measure of both diseased and senesced tissue (Figure 5).

Three applications of epoxiconazole did not give a significant increase on green leaf retention over the untreated control, while the addition of pyraclostrobin as a companion to epoxiconazole gave a small but non-significant increase in \%GLA. Prothioconazole and propiconazole continued to give better control of tan spot (reflected in higher levels of green leaf area) than other fungicides, either alone or as companions in combinations. A triple difenconazole application gave a significant increase in \%GLA. The addition of the SDHI fungicide isopyrazam and the SDHI-containing product prothioconazole plus bixafen to treatments gave significant lifts over basic triazoles in \%GLA. However, the addition of the SDHI containing product epoxiconazole plus fluxapyroxad did not give a significant increase in this parameter.

The grain yields (harvested on 24 January 2014; Figure 6) corresponded closely to the \%GLA assessed 27 days earlier (correlation coefficient of
Figure 4 The mean severity (percentage leaf area affected) of $\tan$ spot on the flag leaf and leaf 2 (L2) of wheat cv. Saracen assessed at GS69 on 9 December 2013 after two applications of fungicides. UTC = untreated control. Bar indicates LSD $(\mathrm{P}=0.05)=10.4$.

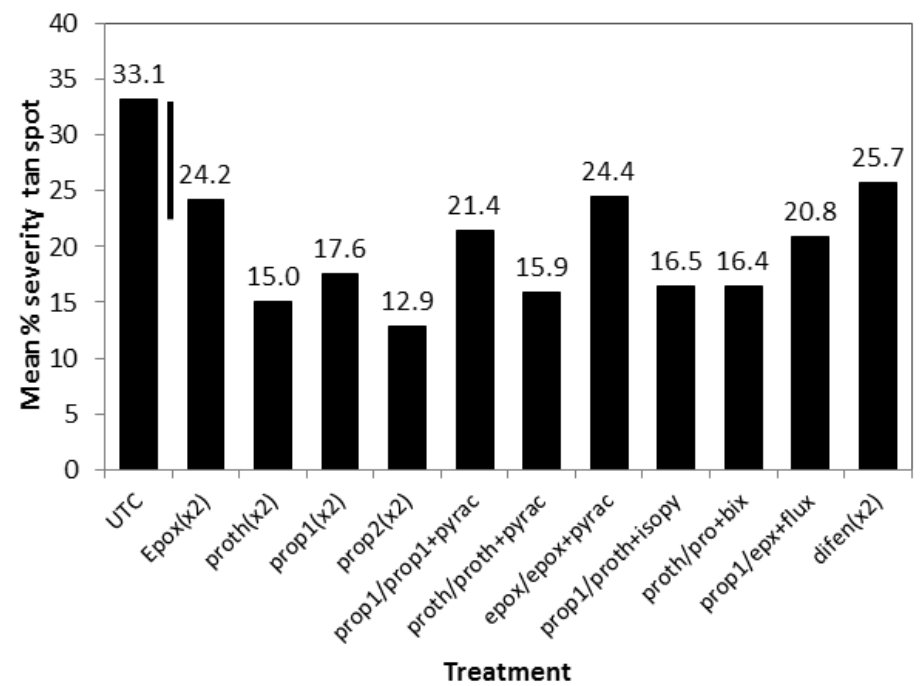




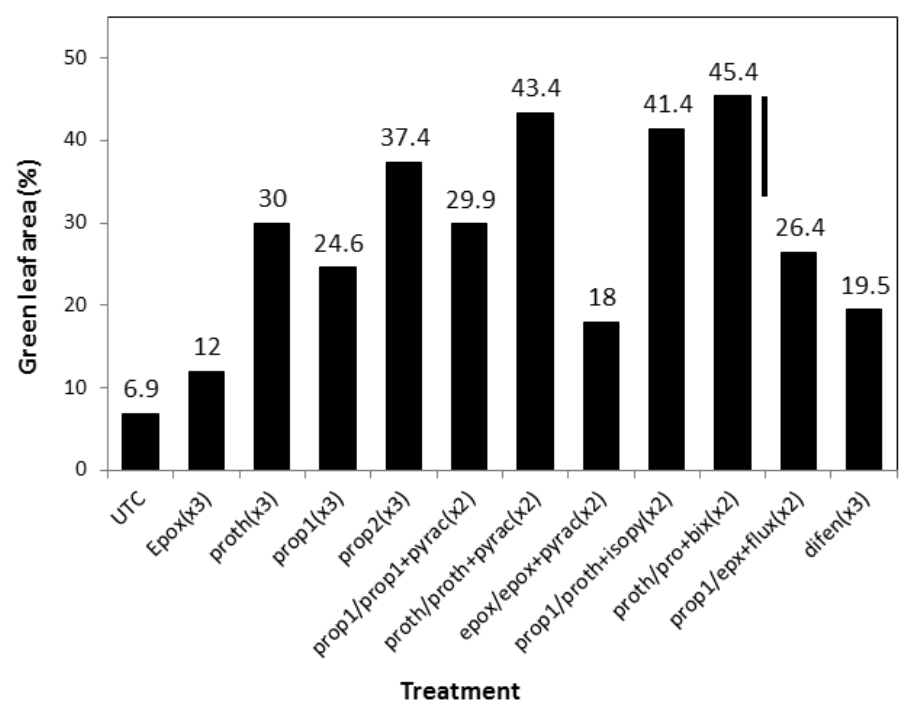

Figure 5 The percentage green leaf area retained on the flag leaf of wheat cv. Saracen assessed at GS85 on 28 December 2013 after three applications of fungicides. $\mathrm{UTC}=$ untreated control. Bar indicates $\operatorname{LSD}(\mathrm{P}=0.05)=12.4$.

0.97). Thus all comments on the performances of the various treatments under \%GLA retention are relevant to the grain yield results.

\section{DISCUSSION}

This is the first reported trial on the control of $\tan$ spot of wheat in New Zealand. The disease was not as widespread over the 2013-14 season as anticipated (S.K. Weith, Lincoln University, personal communication), but in the trial reported here damage to the wheat green leaf area and reduction in subsequent grain yield were severe. This demonstrated the potential of the pathogen to cause severe losses in New Zealand as reported in other wheat growing regions of the world (De Wolf et al. 1998). The application of a range of solo and mixed fungicide treatments applied at three application times reduced the severity of the disease to a certain extent but no treatment completely controlled the infection.

Compared to other irrigated Saracen crops in Canterbury, the grain plot yields in this trial were low, with the highest treatment returning just over $7.6 \mathrm{t} / \mathrm{ha}$ and the untreated control only $6 \mathrm{t} / \mathrm{ha}$ (mean of all treatments $-6.76 \mathrm{t} / \mathrm{ha}$ ). Foundation for Arable Research cultivar trials in Canterbury for the 2013-14 season gave a mean yield of $8.7 \mathrm{t} / \mathrm{ha}$ for $\mathrm{cv}$. Saracen.

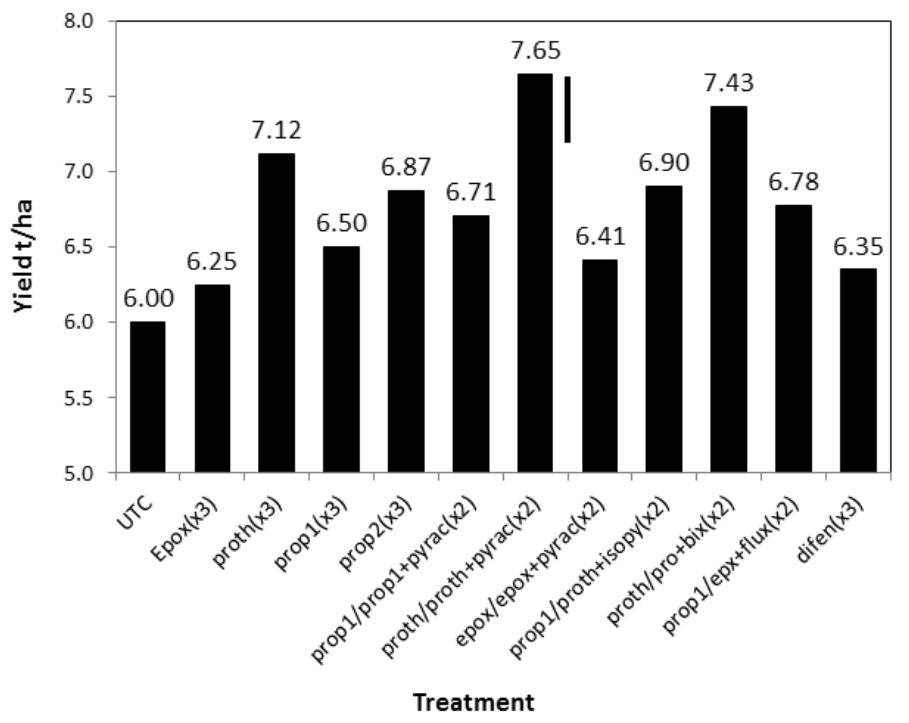

Figure 6 The grain yield of wheat (t/ha) cv. Saracen harvested on 24 January 2014 after three applications of fungicides. UTC $=$ untreated control. Bar indicates $\operatorname{LSD}(\mathrm{P}=0.05)=0.48$. 
These results suggest that the epidemic in the paddock was aggressive and possibly the first fungicides should have been applied earlier to reduce the amount of inoculum in the crop and trial area. Moreover, the moist climatic conditions over the 2013-14 growing season appeared to be highly conducive to disease development and the fungicides were not able to fully restrict the epidemic. No data are available on the susceptibility of the milling wheat $\mathrm{cv}$. Saracen to tan spot in New Zealand and it may not have particularly good resistance or tolerance to the pathogen.

Beard et al. (2009) found in testing 45 isolates in Western Australia to three triazole fungicides that, on average, they were more than twice as sensitive to epoxiconazole compared to propiconazole and tebuconazole. The latter fungicide was not used in the New Zealand trial but contrary results are suggested in the present research in that the pathogen appeared to be more sensitive to propiconazole than epoxiconazole. Propiconazole was reported to be the best fungicide for tan spot control in Brazil (Picinini et al. 1996) and in the trial reported here, propiconazole and the new generation triazole prothioconazole performed equally as well as each other. It should be noted that the fungicide products tested in this trial were not always applied at the recommended label rate because of multiple applications used and they more closely reflect anticipated grower use patterns. Although difenconazole has no registration for use in cereals in New Zealand, it was included in the trial because of its activity against diseases in horticulture crops that are caused by pathogens closely related to $P$. tritici-repentis.

Whether this disease becomes a major concern to wheat growers in New Zealand is unknown at this time. While the application of fungicides may give some control of the disease, the use of stubble management may also be an important control tool. The main method of pathogen over-wintering is reported to be as the sexual or teliomorph (perithecial) state in stubble (CABI 2013). Early cultivation or burning may break the disease cycle and minimise early infection in subsequent wheat crops in the same paddock. Green bridge carry-over may also be important, so the control or elimination of rogue wheat plants in and around known-infected paddocks may also be important. Moreover, the role of seed-borne inoculum in the life cycle of the disease in New Zealand and the effect of seed treatments may also require investigation.

\section{ACKNOWLEDGEMENTS}

We thank the many people at NZ Arable, FAR and PLANTwise Services who contributed to the success of this trial. We thank the farmer for the use of his crop and Sean Weith (Lincoln University) for sharing his knowledge and advice on this disease.

\section{REFERENCES}

Antoni EA, Rybak K, Tucker MP, Hane JK, Solmon PS, Drenth A, Shanka M, Oliver RP 2010. Ubiquity of ToxA and absence of ToxB in Australian populations of Pyrenophora tritici-repentis. Australasian Plant Pathology 39: 63- 68.

Beard C, Loughman R, Smith A, Speijers J 2009. Baseline sensitivity to three triazole fungicides in Pyrenophora tritici-repentis. Australasian Plant Pathology 38: 168-172.

CABI 2013. Pyrenophora tritici-repentis (leaf spot of wheat).CBI Crop Protection Compendium. http://www.cabi.org/publishing-products/ compendia/crop-protection-compendium (accessed 15 April 2015).

De Wolf E, Effertz RJ, Ali S, Francl LJ 1998. Vistas of tan spot research. Canadian Journal of Plant Pathology 20: 349-370.

Hampton JG, Matthews BD 1978. Drechslera spp. on New Zealand certified seed. New Zealand Journal of Agricultural Research 21: 539-542.

Picinini EC, Fernandes JMC Ignaczak JC Ambrosi I 1996. Economic impact due to propiconazole use on wheat. Fitopatologia Brasileira 21: 362-368. 